Abstract-A stock assessment incorporating sensitivity in biological parameters and potential fishery management strategies for wahoo (Acanthocybium solandri) in the southwest Pacific Ocean was undertaken to assess the stock status of this species for 2008-2010. Selectivity probabilities at age were similar for 2 commercial longline fisheries and a recreational sport fishery. However, the median exploited length and age were slightly higher in the commercial fisheries than in the recreational fishery. Current fishing mortality $\left(F_{\text {current }}\right)$ was predicted to be lower than limit and target reference points, with the exception that $F_{\text {current }}$ exceeded the target reference point $F_{\text {SSB } 40}$ (fishing mortality at which the spawning stock biomass per recruit $[\mathrm{SSB} / \mathrm{R}]$ is $40 \%$ of the $\mathrm{SSB} / \mathrm{R}$ at $F=0$ ). This result indicates that wahoo may be at a greater risk of recruitment overfishing than of growth overfishing. Of the fishery management scenarios tested, introduction of a slot limit in the recreational fishery had the greatest effect on assessment results; however, this effect was relatively minor and may not be practical to implement. Given the relatively short life span of wahoo, ongoing biological monitoring and rigorous collection of catch and effort data may facilitate continued assessment of this species in the southwest Pacific Ocean.

Manuscript submitted 20 March 2014. Manuscript accepted 21 July 2015.

Fish. Bull. 113:407-418 (2015)

Online publication date: 10 August 2015. doi: 10.7755/FB.113.4.4

The views and opinions expressed or implied in this article are those of the author (or authors) and do not necessarily reflect the position of the National Marine Fisheries Service, NOAA.

\title{
Per-recruit stock assessment of wahoo (Acanthocybium solandri) in the southwest Pacific Ocean
}

\author{
Mitchell T. Zischke (contact author) ${ }^{1,2}$ \\ Shane P. Griffiths ${ }^{2}$ \\ Email address for contact author: mitchell.zischke@gmail.com \\ 1 School of Biological Sciences \\ The University of Queensland \\ Brisbane, Queensland 4072, Australia \\ Present address: Purdue University \\ Department of Forestry and Natural Resources \\ 195 Marsteller St \\ West Lafayette, Indiana 47907, United States \\ 2 Oceans and Atmosphere Flagship \\ Commonwealth Scientific and Industrial Research Organisation \\ GPO Box 2583 \\ Dutton Park, Queensland 4102, Australia
}

Wahoo (Acanthocybium solandri) is a pelagic scombrid with a tropical and subtropical distribution in oceanic waters worldwide (Collette and Nauen, 1983). This species is caught incidentally and retained as a byproduct in commercial pelagic longline, purse-seine, and trolling fisheries that target tunas and mackerels (Scombridae), broadbill swordfish (Xiphias gladius), and dolphinfishes (Coryphaena spp.) (Zischke, 2012). The average annual global catch of wahoo in these fisheries has remained around 3000 metric tons ( $t$ ) since 1996 (Global Production Statistics 1950-2012, FAO, available at website, accessed October 2012). Commercial catches in the Pacific Ocean have increased 10-fold over the past 15 years (Global Production Statistics 1950-2012, FAO) because of increases in effort in tuna fisheries in this region. Wahoo is also an important target and nontarget species in subsistence and artisanal fisheries, as well as a prized catch in recreational fisheries throughout the west- ern Pacific Ocean (Zischke, 2012). Although catch and effort data from subsistence, artisanal, and recreational fisheries are scarce, evidence indicates that the recreational catch of wahoo may exceed the commercial catch off eastern Australia (Zischke et al., 2012), as has been reported for the Atlantic Ocean $\left(\mathrm{SAFMC}^{1}\right)$.

Off eastern Australia, wahoo are retained as byproduct in the Commonwealth-managed Eastern Tuna and Billfish Fishery (ETBF). The ETBF is a pelagic longline fishery with a quota on species that include albacore (Thunnus alalunga), yellowfin tuna (T. albacares) and bigeye tuna (T. obesus), as well as broadbill

\footnotetext{
1 SAFMC (South Atlantic Fishery Management Council). 2003. Fishery management plan for the dolphin and wahoo fishery of the Atlantic including a final environmental impact statement, regulatory impact review, initial regulatory flexibility analysis, and social impact assessment/fishery impact statement, 308 p. SAFMC, Charleston, SC. [Available at website].
} 
swordfish and striped marlin (Kajikia audax) (AFMA ${ }^{2}$ ). The mean annual catch of wahoo in the ETBF has been $20.1 \mathrm{t}$ (standard error [SE] 2.7) over the last 15 years, and the majority of catch has been derived from the northeastern area of Australia's Exclusive Economic Zone (EEZ) $\left(\mathrm{AFMA}^{3}\right)$. Apart from an arbitrary combined possession limit for wahoo, butterfly mackerel (Gasterochisma melampus) and slender tuna (Allothunnus fallai) of 20 fish per trip (AFMA ${ }^{2}$ ), no speciesspecific assessment or management framework exists for wahoo in this fishery. Wahoo also are caught in low quantities ( $<5 \mathrm{t}$ annually) in state-managed trolling fisheries that target narrow-barred Spanish mackerel (Scomberomorus commerson) in Queensland and New South Wales (DAF ${ }^{4}$; DPI ${ }^{5}$ ).

Elsewhere in the southwest Pacific Ocean, wahoo are retained as byproduct in the commercial pelagic longline fishery of New Caledonia, which targets species similar to those targeted by the ETBF. Catch of wahoo in this fishery is similar to the ETBF, with a mean annual catch of $25.1 \mathrm{t}$ (SE 3.5) since 1997. No management measures exist for wahoo in this fishery.

Specialized recreational fisheries exist for wahoo off eastern Australia, and, although total catch is poorly understood, recent evidence indicates that it may be equal to or exceed the total commercial catch in some regions (Zischke et al., 2012). Management measures for recreational fisheries differ by state: a minimum legal length of $75 \mathrm{~cm}$ in total length (TL) and a possession limit of 2 fish per person has been mandated in Queensland (according to the Queensland Fisheries Regulation 2008) but there is no minimum legal length and a possession limit of 5 fish per person in New South Wales (according to the New South Wales Fisheries Management [General] Regulation 2010).

Wahoo are low priority as a commercial species, a status that is likely to be responsible for the lack of biological research on the species that has hindered the undertaking of rigorous stock assessments (Zischke, 2012). However, preliminary stock assessments have been completed for wahoo in the Atlantic Ocean and the waters off Taiwan. The Atlantic assessment in 2000 considered wahoo in the subtropical western North Atlantic, Caribbean, and Gulf of Mexico to be a single stock and used median annual catch as a proxy for fishing mortality $(F)$ to indicate a maximum sustainable yield (MSY) of 640-740 t, but an assessment of the current status of the stock was not undertaken

2 AFMA (Australian Fisheries Management Authority). 2011. Eastern Tuna and Billfish Fishery (ETBF) management arrangements booklet: 2011 fishing season, 31 p. AFMA, Canberra, Australia. [Available at website].

${ }^{3}$ AFMA (Australian Fisheries Management Authority). 2011. Unpubl. data. [Eastern Tuna and Billfish Fishery commercial logbook data.] AFMA, Canberra, 2610, Australia.

${ }^{4}$ DAF (Department of Agriculture and Fisheries). 2011. Unpubl. data. [Queensland commercial and charter fisheries logbook data.] Queensland DAF, Brisbane, 4001, Australia.

${ }^{5}$ DPI (Department of Primary Industries). 2011. Unpubl. data. [New South Wales commercial fisheries logbook data.] New South Wales DPI, Port Stephens, 2316, Australia.
(SAFMC ${ }^{1}$ ). In the waters off Taiwan, an age-structured model was used in 2007 to assess the current fishing mortality $\left(F_{\text {current }}\right)$ against the reference points of 1 ) fishing mortality at which the slope of the yield-perrecruit (Y/R) curve is $10 \%$ of the slope at the origin $\left(F_{0.1}\right)$ and 2$)$ the fishing mortality at which the spawning stock biomass per recruit $(\mathrm{SSB} / \mathrm{R})$ is $40 \%$ of the $\mathrm{SSB} / \mathrm{R}$ at $F=0\left(F_{\mathrm{SSB} 40}\right)$ obtained from a Y/R model, and results from that model indicated that wahoo were being fished at sustainable levels (Lee, 2008).

Despite exploitation by multiple fishing sectors and an increasing commercial catch in the southwest $\mathrm{Pa}$ cific Ocean, no stock assessment has been completed for wahoo in this region. Recent research has provided comprehensive information on the stock structure, age, growth, and reproductive biology of this species in this region (Zischke et al., 2013a; 2013b; 2013c). Wahoo grow quickly and reach sexual maturity at less than 1 year old (Zischke et al., 2013a; 2013b). Most wahoo in fisheries catches, and their populations in general, are 1-2 years old. Biological data, in conjunction with fishery data from Australia and New Caledonia, were used to conduct the first stock assessment for wahoo in the southwest Pacific Ocean, and we present the results here. The objectives of the present study were 1) to apply an age-structured per-recruit model to the wahoo stock, 2) to examine the sensitivity of the population status derived by a per-recruit model after incorporating variability in biological parameters, and 3) to investigate potential management strategies for ensuring the long-term sustainability of wahoo in this region.

\section{Materials and methods}

\section{Study area}

The global stock structure of wahoo is uncertain. Although the species is reputed to exist as a single panmictic population worldwide (Theisen et al., 2008), recent evidence suggests that wahoo may exist as multiple phenotypic populations throughout the Pacific Ocean (Zischke et al., 2013c). A fine-scale, spatially explicit analysis of morphometrics and parasites has indicated that wahoo off eastern Australia form part of a single stock in the southwest Pacific Ocean (Zischke et al., 2013c). Because the geographic extent of this stock has not been resolved, we have adopted a precautionary approach, defining the stock for assessment as consisting of wahoo from the EEZ off eastern Australia and the EEZ of New Caledonia (Fig. 1).

\section{Fishery data used for stock assessment}

Limited catch and effort data are available for wahoo in the southwest Pacific Ocean because wahoo are not targeted in any commercial fisheries and are taken as part of the specialized recreational sport fishery in this region (Zischke, 2012; Zischke et al., 2012). In the 
ETBF, catch, effort, and CPUE (catch per unit of effort) data for wahoo has been recorded in commercial logbooks since $1996\left(\mathrm{AFMA}^{3}\right)$. Similarly, in the commercial pelagic longline fishery in New Caledonia, logbook data have been recorded since 1997 (SPC6).

In addition to catch and effort data in commercial longline fisheries, size composition data are available for most fisheries. For Australian fisheries, onboard scientific observers from the Australian Fisheries Management Authority have recorded size composition data for wahoo in the ETBF since 2002. No catch and effort data are available from recreational fisheries. However, limited size composition data from the recreational fishery off eastern Australia (EC Rec) are available from an on-site survey of this fishery in 2010 (Zischke et al., 2012), as well as from a volunteer tagging program since $1973\left(\mathrm{DPI}^{7}\right)$. Limited size composition data from commercial and recreational fisheries off eastern Australia also are available from biological research conducted between 2008 and 2011 (Zischke et al., $2013 \mathrm{a} ; 2013 \mathrm{~b})$. To supplement data from Australian fisheries, size composition data were obtained from observers and port samplers in the fishery in New Caledonia $\left(\mathrm{SPC}^{6}\right)$.

Size composition data from all fisheries were restricted to the period 20082010 for all analyses because biological data were collected during this period. Age distributions were calculated by converting fork length (FL) to age with a von Bertalanffy growth function reported by Zischke et al., 2013b (Table 1), who noted that age could not be calculated for any fish with an FL greater than the maximum theoretical fork length $\left(L_{\infty}\right)$ because such a fish would be assigned an infinite age.

\section{Estimation of mortality}

Natural mortality is a key component of fish stock dynamics because it directly influences the productivity of a stock and the optimum fishery yield that can be obtained. One of the most reliable methods for estimating the natural mortality of a stock is through mark-recapture experiments (Vetter, 1988). However, such experiments are expensive to implement and re-

\footnotetext{
${ }^{6}$ SPC (Secretariat of the Pacific Community). 2011. Unpubl. data [Commercial fisheries logbook data.] SPC, 98848 Noumea, New Caledonia.

7 DPI (Department of Primary Industries). 2011. Unpubl. data [Gamefish Tagging Program tagging data.] New South Wales DPI, Port Stephens, 2316, Australia.
}

quire extensive fishing effort to ensure high numbers of initial marking and adequate recaptures for analysis. Mark-recapture work was outside the scope of this study; therefore, 2 empirical equations were used to provide estimates of natural mortality $(M)$ of wahoo in the southwest Pacific Ocean.

The first model was that of Pauly (1980):

$$
\begin{gathered}
\log M=-0.0066-0.279 \log L_{\infty}+0.6543 \log K \\
+0.4634 \log T,
\end{gathered}
$$

where $L_{\infty}$ and $K=$ von Bertalanffy growth parameters (Table 1), respectively (Zischke et al., 2013b); and

$T=$ the mean sea-surface temperature off eastern Australia at $22.9^{\circ} \mathrm{C}\left(\mathrm{CSIRO}^{8}\right)$.

The second model used to estimate $M$ was that of Hoenig (1983):

$$
M=\frac{-\ln (0.01)}{t_{\mathrm{m}}},
$$

\footnotetext{
${ }^{8}$ CSIRO (Commonwealth Scientific and Industrial Research Organisation). 2012. Unpubl. data. [Sea-surface temperature data.] CSIRO, Dickson ACT 2602, Australia.
} 


\section{Table 1}

Means and 95\% confidence intervals (CI) for biological parameters used in the stock assessment of wahoo (Acanthocybium solandri) in the southwest Pacific Ocean during 2008-2010. TL=total length, $\mathrm{FL}=$ fork length, $W_{\mathrm{B}}=$ body weight, $\mathrm{VBGF}=$ von Bertalanffy growth function, $L_{\mathrm{t}}=$ length at time $t$, and $m_{\mathrm{L}}=$ maturity at length. Length, weight, and VBGF parameters $\left(L_{\infty}, K\right.$, and $\left.t_{0}\right)$ were obtained from Zischke et al. (2013b), and maturity parameters were obtained from Zischke et al. (2013a).

\begin{tabular}{llcrc}
\hline Model & \multicolumn{1}{c}{ Equation } & Parameter & Mean & $95 \%$ CI \\
\hline TL (mm) and FL (mm) & $T L=a F L+b$ & $a$ & 1.01 & $1.00-1.02$ \\
& & $b$ & 34.97 & $26.23-43.71$ \\
$\mathrm{~W}_{\mathrm{B}}(\mathrm{g})$ and FL(mm) & $\log W_{B}=a \log F L+b$ & $a$ & 3.28 & $3.20-3.36$ \\
& & $b$ & -13.95 & $-14.01-13.89$ \\
$\mathrm{VBGF}$ & $L_{\mathrm{t}}=L_{\infty}\left[1-\mathrm{e}^{-\mathrm{K}\left(\mathrm{t}-\mathrm{t}_{0}\right)}\right]$ & $L_{\infty}$ & 1498.65 & \\
& & $K$ & 1.58 & $1.23-1.93$ \\
$1465.80-1531.50$ & & $t_{0}$ & -0.17 & $-0.35-0.01$ \\
& $m_{\mathrm{L}}=\frac{e^{-\mathrm{a}+\mathrm{bL}}}{1+e^{-\mathrm{a}+\mathrm{bL}}}$ & $a$ & -16.98 & $-22.25--11.71$ \\
Maturity & & $b$ & 0.02 & $0.01-0.02$
\end{tabular}

where $t_{\mathrm{m}}=$ a maximum age of 7 years (Zischke et al., 2013b). In the absence of exploitation, it was assumed that $1 \%$ of fish in the population would reach $t_{\mathrm{m}}$ (Quinn and Deriso, 1999). An estimate of 7 years for $t_{\mathrm{m}}$ was based on the maximum observed age in a biological study in the southwest Pacific Ocean (Zischke et al., 2013b). However, because wahoo may reach an age greater than that observed in the study by Zischke et al. (2013b), and have undergone exploitation by commercial and recreational fisheries for at least 15 years, this estimate should be viewed with caution.

Age-based catch curves are often used to estimate the annual instantaneous mortality rate $(Z)$ according to the description of Beverton and Holt (1957). However, for tropical species that have fast growth and a short lifespan, length-converted catch curves may be more useful (Sparre et al., 1989). Therefore, length-frequency data from the 3 fisheries (i.e., the 2 commercial fisheries, ETBF and New Caledonia, and the EC Rec) were used to construct length-converted catch curves according to the methods of Pauly (1983, 1984a, 1984b). Size-frequency data were converted to age-frequency data with the von Bertalanffy growth parameters (Table 1; Zischke et al., 2013b).

Selectivity may differ with fish size or age, as well as with different fisheries, especially for those fisheries that use different gear types. Total mortality at age $\left(Z_{\mathrm{t}}\right)$ can be expressed in an equilibrium state in this way:

$$
\begin{aligned}
Z_{\mathrm{t}}= & M_{\mathrm{t}}+S_{\mathrm{t}}^{\mathrm{ETBF}} F_{\mathrm{t}}^{\mathrm{ETBF}}+S_{\mathrm{t}}^{\mathrm{EC} \mathrm{Rec}} F_{\mathrm{t}}^{\mathrm{EC} \mathrm{Rec}} \\
& +S_{\mathrm{t}}^{\text {New Cal }} F_{\mathrm{t}}^{\text {New Cal }}
\end{aligned}
$$

where $M_{\mathrm{t}}=$ the natural mortality at age $t$; and

$S_{\mathrm{t}}$ and $F_{\mathrm{t}}=$ the selectivity and fishing mortality at age for the ETBF, EC Rec, and New Caledonia (New Cal) fisheries, respectively.
Selectivity at age in each fishery was estimated with standard linear length-converted catch curves by using backward extrapolation of the descending regression line to include younger fish that were likely to be under-represented in catches (Sparre et al., 1989). All fisheries in this study were hook-and-line fisheries, which tend to have selectivity probabilities that follow a logistic function because the fishing gear is capable of catching any fish larger than the size at which all fish are recruited to the fishery (Hovgard and Lassen, $2000)$. Therefore, the selectivity $\left(S_{\mathrm{t}}\right)$ at age $(t)$ in each fishery was determined with the following equation:

$$
S_{\mathrm{t}}=\frac{1}{1+e^{\mathrm{a}+\mathrm{bt}}}
$$

where $a=$ the intercept; and

$b=$ the slope of a linear regression line fitted to the observed selection at age (Sparre et al., 1989).

Numbers of fish in each age class for each fishery were adjusted according to their respective selectivity probability before the catch-curve analysis. Given the similar selectivity of the 3 fisheries (see Results section), an estimate of $Z$ was obtained from the slope of a linear regression line fitted to a length-converted catch curve for all fisheries combined, and instantaneous $F$ was calculated as $F=Z-M$.

\section{Per-recruit analysis}

The Y/R and SSB/R of wahoo in the southwest Pacific Ocean were assessed by using the model of Quinn and Deriso (1999). This model defines the age-specific exploitation fraction $\left(\mu_{t}\right)$ in this manner:

$$
\mu_{\mathrm{t}}=\frac{F_{\mathrm{t}}}{F_{\mathrm{t}}+M}\left(1-e^{-\Delta \mathrm{t}\left(F_{\mathrm{t}}+M\right)}\right),
$$


where $\Delta t=$ the change in age; and

$F_{t}=$ the fishing mortality at age, which is a product of fishing mortality and selectivity at age for each fishery:

$$
F_{\mathrm{t}}=\sum_{\mathrm{j}} S_{\mathrm{t}, \mathrm{j}} F_{\mathrm{j}}=\sum_{\mathrm{j}} F_{\mathrm{t}, \mathrm{j}}
$$

where $S_{\mathrm{t}, \mathrm{j}}=$ the selectivity at age; and

$F_{\mathrm{j}}=$ the fishing mortality of the $j$ th fishery (Quinn and Deriso, 1999).

A recent reproductive study for wahoo off eastern Australia reported the FL at which 50\% of females are mature $\left(L_{50}\right)$ as $1046 \mathrm{~mm}$, which corresponds to an age at $50 \%$ maturity $\left(A_{50}\right)$ of approximately 7 months (Zischke et al., 2013a). No estimate of $L_{50}$ was reported for male wahoo; however, as growth parameters do not differ significantly between sexes (Zischke et al., 2013a), it is assumed to be similar to that of females. The maturity-at-length $\left(m_{\mathrm{L}}\right)$ logistic function reported in this study was used to calculate SSB/R (Table 1).

Wahoo are exploited by multiple fisheries, including recreational sport fisheries that often practice catch and release; therefore, it is important to account for the effect of discard mortality on stock biomass. Discard mortality is the product of the probability that a fish is discarded and the probability that, if released, the fish still dies because of the physiological stress of capture. Discard mortality at age $\left(H_{\mathrm{t}}\right)$ is likely to be fishery specific, where the fishing mortality for the $j$ th fishery $\left(F_{\mathrm{j}}^{\prime}\right)$ can be expressed with the following equation:

$$
F_{\mathrm{j}}^{\prime}=-\ln \left(1-H_{\mathrm{t}, \mathrm{j}}\left(1-e^{-F_{\mathrm{t}, \mathrm{j}}}\right)\right),
$$

where $F_{\mathrm{t}, \mathrm{j}}=$ a product of the fishing mortality at age and the selectivity at age (Quinn and Deriso, 1999; see Eq. 6).

Postrelease mortality is expensive to evaluate, particularly for large oceanic fishes, and there is currently no species-specific estimate for wahoo. Two electronic tagging studies of wahoo have reported relatively low levels of postrelease mortality. Theisen (2007) deployed pop-up satellite archival tags on 3 wahoo in the Atlantic Ocean, and all fish survived more than 5 days after release, a time period that is often used to assess postrelease mortality (Domeier et al., 2003; Kerstetter and Graves, 2006). In the eastern Pacific Ocean, Sepulveda et al. (2011) deployed 108 archival tags on wahoo caught by using recreational fishing techniques and had up to $62 \%$ tag recovery in areas with high fishing effort. These results indicate that postrelease mortality may be relatively low. Similarly, for juvenile bluefin tuna (T. thynnus), another scombrid, in the Atlantic Ocean, Skomal et al. (2002) reported postrelease mortality of $28 \%$ when recreational fishing techniques were used. As such, we assumed the postrelease mortality of wahoo from the EC Rec was also 28\%. Approximately $6-38 \%$ of wahoo were reported as released by the EC
Rec (Zischke et al., 2012). Assuming a mean release percentage of $20 \%$, combined with a postrelease mortality of 28\%, the percentage of fish at age $t$ incurring mortality in the EC Rec fishery is $86 \%$, or $H_{\mathrm{t}}=0.86$.

Discard mortality may be higher for pelagic longline fisheries because a large proportion of fish are already dead once they are hauled onto a vessel (Kerstetter and Graves, 2008). Observer data from the ETBF were investigated to identify the life status of wahoo upon hauling-ranging from dead and in rigor mortis to alive and vigorous. Less than $10 \%$ of wahoo were alive (sluggish or vigorous) upon hauling, and only $3 \%$ of all wahoo were released. As such, it was assumed that $100 \%$ of longline-caught fish died $\left(H_{\mathrm{t}}=1.0\right)$.

Per-recruit analysis was undertaken by using an age-structured virtual population model with 1-month time intervals to capture the variability in the biological dynamics of wahoo (e.g., growth and maturity) that occurs primarily within the first year of life (Zischke et al., 2013a; Zischke et al., 2013b). To assess the status of the wahoo stock in the study area, $F_{\text {current }}$ was compared with 2 limit and 2 target reference points. From the Y/R analysis, the limit reference point was the fishing mortality at which maximum $\mathrm{Y} / \mathrm{R}$ is produced $\left(F_{\max }\right)$, and the target reference point was $F_{0.1}$. For the SBB/R analysis, the limit and target reference points were defined as the fishing mortality at which the $\mathrm{SSB} / \mathrm{R}$ is $25 \%$ of the $\mathrm{SSB} / \mathrm{R}$ at $F=0\left(F_{\mathrm{SSB} 25}\right)$ and as $F_{\text {SSB40 }}$, respectively.

\section{Sensitivity and management simulations}

A sensitivity analysis was conducted to examine the effect of variability in growth and maturity estimates on Y/R and SSB/R. Rather than use mean biological parameters, new parameters were randomly selected from a normal distribution defined by the mean and standard error for each parameter (Table 1). Randomly selected parameters were used in all subsequent calculations, including $M$ (Eq.1 only), catch-curve analysis, selectivity, and the per-recruit analysis. To investigate uncertainty in stock assessment outputs under this scenario (S1), 100 model iterations were conducted. With this scenario, $M$ is assumed to be constant throughout the life of a fish; however, $M$ has been shown to vary ontogenetically in pelagic tunas and may be an order of magnitude higher for small fishes (Hampton, 2000). To examine variable mortality for wahoo, we also ran a scenario (S2) in which natural mortality at age was set at an order of magnitude higher for fish 0-2 months old and mortality for all other age classes (i.e., $>2$ months old) remained unchanged.

To assess the efficacy of potential fishery management measures, a number of model scenarios were explored with the same iterative approach outlined previously. Currently, the only size restriction for wahoo in any Australian recreational fishery is a minimum legal length of $75 \mathrm{~cm}$ TL in Queensland. Because $L_{50}$ is considered to be $104.6 \mathrm{~cm}$ TL (Zischke et al., 2013a), for the first fishery management scenario 

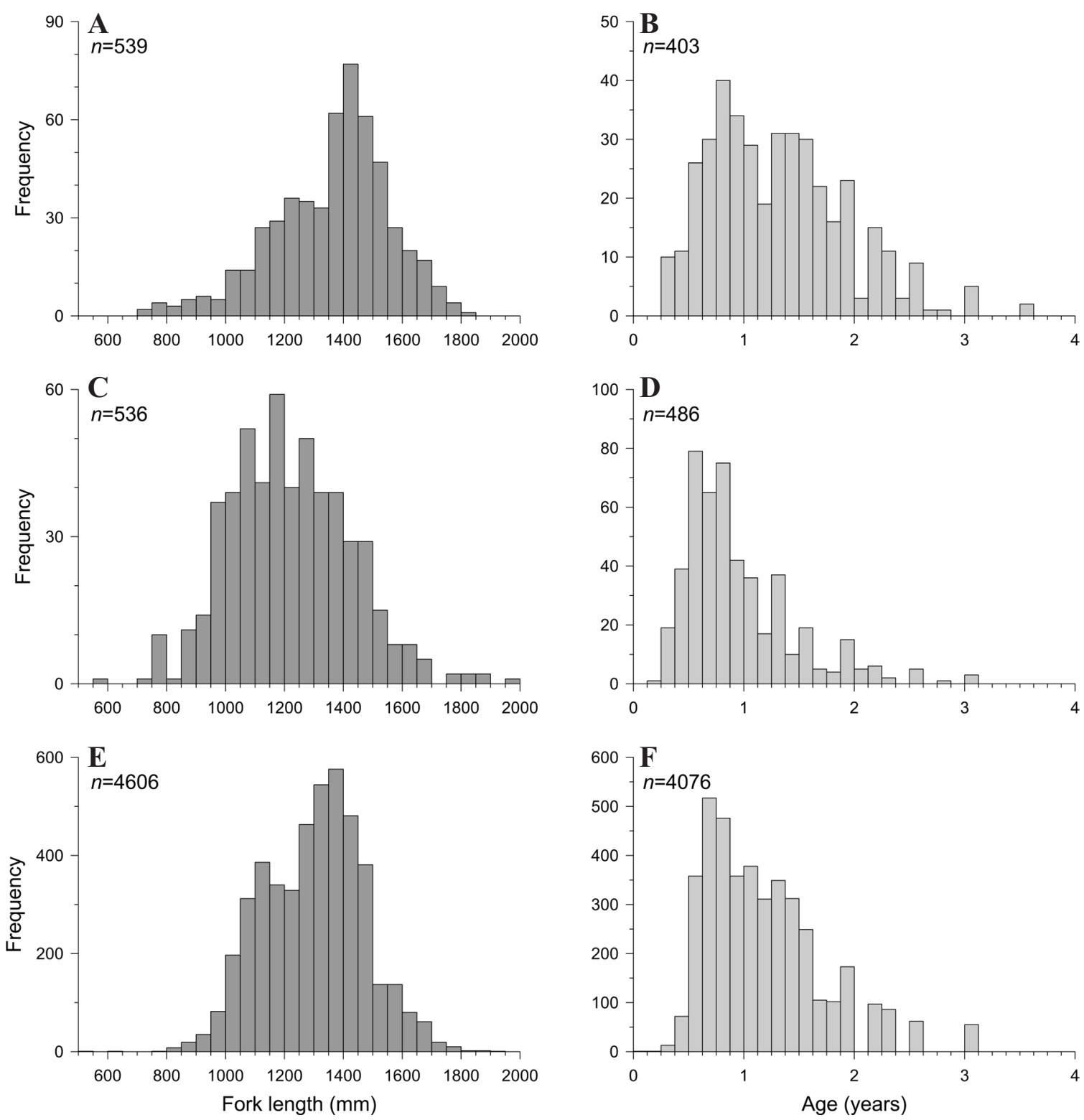

Figure 2

Length- and age-frequency distributions of wahoo (Acanthocybium solandri) caught in the (A and B) Eastern Tuna and Billfish Fishery $(\mathbf{C}$ and $\mathbf{D})$ recreational fishery off eastern Australia and (E and $\mathbf{F}$ ) the commercial longline fishery in New Caledonia between 2008 and 2010. Note that the sample sizes were lower for agefrequency distributions because age could not be calculated for all fish with a fork length greater than the theoretical length of infinite age (i.e., FL>1499 mm).

(F1), the effect of imposing a minimum legal length of $100 \mathrm{~cm}$ TL for the entire recreational fishery was explored. Although this length is slightly smaller than $L_{50}$, its simplicity may be easier for recreational fishermen to remember and management agencies to enforce. For scenarios F2 and F3, variations of these size limits were examined, including a maximum legal length of $150 \mathrm{~cm}$ TL (based on size distributions for the recreational fishery; see Fig. 2), and a slot limit where only fish $100-150 \mathrm{~cm}$ TL may be retained, respectively. As the $F$ from the recreational sector represents only about one-third of the total $F$ in the southwest Pacific Ocean, we used an additional scenario (F4) to explore changes to commercial longline fisheries. This scenario reduced the postrelease mortality of wahoo from $90 \%$ to $50 \%$, following the hypo- 


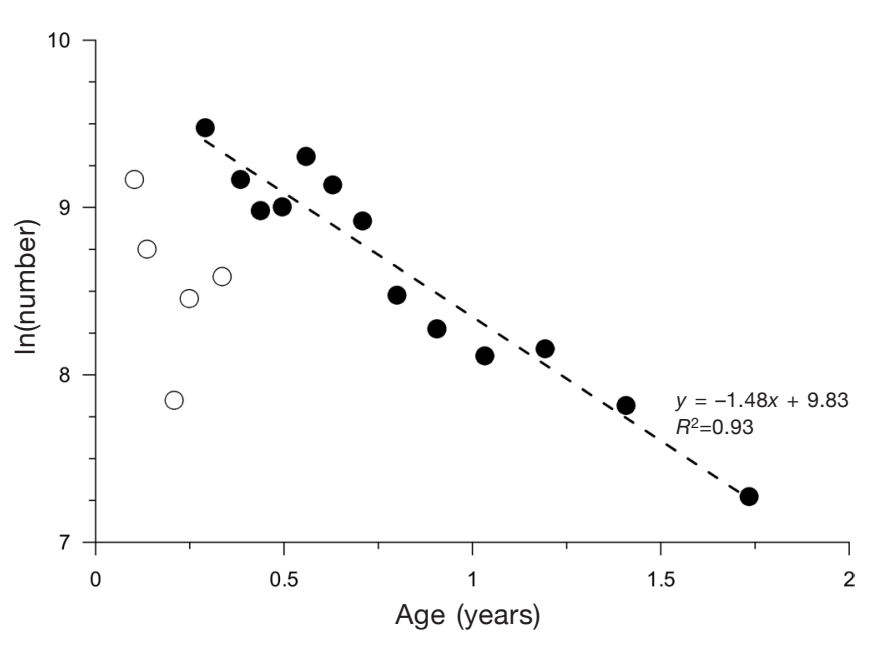

Figure 3

A length-converted catch curve for wahoo (Acanthocybium solandri) in the southwest Pacific Ocean (all fisheries combined) between 2008 and 2010. Numbers of fish in each age class were corrected with selectivity probability at age for all fisheries combined. Only values indicated by the solid black symbols were used in the regression analysis to estimate total mortality. $R^{2}=$ coefficient of multiple determination.

thetical implementation of shorter soak times in the pelagic longline fishery, thereby allowing more fish to remain alive at haul back, and introduced a $20 \%$ discard rate similar to that observed for the recreational fishery. All analyses were undertaken with $\mathrm{R}$ software, vers. 3.0.2 (R Core Team, 2013).

\section{Results}

\section{Size and age structure of exploited wahoo}

Length- and age-frequency distributions of wahoo were similar for the 3 fisheries examined in the southwest Pacific Ocean, but the recreational fishery tended to catch slightly smaller and younger fish (Fig. 2). The median FLs for the ETBF, New Caledonia, EC Rec were $1400 \mathrm{~mm}$ (mean: 1366), 1320 (1304) $\mathrm{mm}$, and 1209 (1222) $\mathrm{mm}$. Corresponding median ages for the ETBF, New Caledonia, and EC Rec were 1.25 (mean: 1.31) years, 1.08 (1.18) years, and 0.82 (0.95) years. These median and mean ages are underestimates, however, because age could not be calculated for fish with an FL greater than $1499 \mathrm{~mm}$ (i.e., $L_{\infty}$ ).

\section{Age and size selectivity of fisheries}

The selectivity probability at age for wahoo was similar for the 3 fisheries. The age (and FL) at which $50 \%$ of wahoo were selected in the ETBF, EC Rec, and New Caledonia was 0.58 years (mean: $1041 \mathrm{~mm}$ ), 0.60 years (1055 mm), and 0.63 years $(1076 \mathrm{~mm})$, respectively.

\section{Mortality estimates}

Estimates of $M$ obtained from the use of mean biological parameters (Table 1) in the 2 empirical equations were 0.66-0.74/year. Catch-curve analysis where the mean biological parameters for all fisheries were combined between 2008 and 2010 produced an estimate of $Z$ of 1.48 /year (Fig. 3 ). Subtracting $M$ from $Z$, the annual $F_{\text {current }}$ for wahoo in the southwest Pacific Ocean was estimated as $0.74-0.82 /$ year.

\section{Sensitivity and management simulations}

In the base scenario (S1), $F_{\text {current }}$ was lower than both limit reference points (i.e., $F_{\max }$ and $F_{\mathrm{SSB} 25}$ ) and the target reference point $F_{0.1}$, but it was higher than $F_{\text {SSB40 }}$ (Table 2 ). Introduction of a 10 -fold increase in $M$ for young fish (S2) caused a decrease in overall Y/R and SSB/R (Fig. 4) but resulted in $F_{\text {current }}$ exceeding the reference points in a lower percentage of iterations than the percentage seen in S1 (Table 2). In all of the fishery management scenarios (F1-F4) examined, $F_{\text {cur- }}$ rent was lower than all reference points (Table 2). Scenario F2 produced the most favorable results with respect to Y/R as $F_{\text {current }}$ exceeded the target and limit reference points in $2 \%$ and $0 \%$ of iterations (Table 2). With respect to SSB/R, scenario F3 produced the most favourable results, as $F_{\text {current }}$ exceeded the target and limit reference points in $27 \%$ and $2 \%$ of iterations (Table 2 ).

\section{Discussion}

\section{Size selectivity of fisheries}

The 3 fisheries examined in this study had similar selectivity probabilities at age; however, there were differences in the size distribution of wahoo caught in these fisheries, particularly between the commercial and recreational fisheries off eastern Australia. Numerous characteristics of pelagic longline gear may influence the probability of capture. These characteristics include the time of day (i.e., night or day) when the gear is soaking in relation to the peak feeding times of wahoo, the depth of hooks in relation to the depth distribution of the fish, and the size of the hook (and bait) relation to the maximum gape of the mouth. For example, in a trial where circle hooks were $57 \%$ wider than the traditional Japanese tuna hooks resulted in lower catch rates of smaller nontarget species, including wahoo (Curran and Bigelow, 2011). Circle hooks are widely used in the ETBF; and, therefore, these larger hooks may select for larger fish.

Recreational fishing gear used to catch wahoo (either intentionally or incidentally) off eastern Australia varies considerably among individual fishermen and includes heavy tackle, large hooks, baits, and lures used 
Table 2

Results of the per-recruit analysis for wahoo (Acanthocybium solandri) in the southwest Pacific Ocean during 2008-2010 under sensitivity (S1-S2) and fishery management scenarios (F1-F4). For each scenario, means and 95\% confidence intervals (CI) are given for current fishing mortality $\left(F_{\text {current }}\right)$ and 4 biological reference points: fishing mortality at which maximum yield per recruit is produced $\left(F_{\max }\right)$, fishing mortality at which the slope of the yield-per-recruit curve is $10 \%$ of the slope at the origin $\left(F_{0.1}\right)$, and fishing mortalities at which the spawning stock biomass per recruit (SSB/R) is $25 \%\left(F_{\mathrm{SSB} 25}\right)$ and $40 \%$ $\left(F_{\mathrm{SSB} 40}\right)$ of the SSB/R at $F=0$. For each scenario, 100 iterations were conducted, and the percentage of iterations in which $F_{\text {current }}$ exceeded the reference point are given here for each scenario.

\begin{tabular}{|c|c|c|c|c|c|c|c|c|c|}
\hline \multirow[b]{2}{*}{$\begin{array}{l}\text { Model } \\
\text { scenario }\end{array}$} & \multirow[b]{2}{*}{$\begin{array}{c}\text { Mean }(95 \% \mathrm{CI}) \\
F_{\text {current }}\end{array}$} & \multicolumn{2}{|c|}{$\begin{array}{l}\text { Mean }(95 \% \mathrm{CI}) \\
\text { target reference points }\end{array}$} & \multicolumn{2}{|c|}{$\begin{array}{c}\text { Mean }(95 \% \text { CI }) \\
\text { limit reference points }\end{array}$} & \multicolumn{2}{|c|}{$\begin{array}{c}\text { Iterations in } \\
\text { which } F_{\text {current }} \\
\text { exceeds target } \\
\text { reference } \\
\text { points }(\%)\end{array}$} & \multicolumn{2}{|c|}{$\begin{array}{c}\text { Iterations in } \\
\text { which } F_{\text {current }} \\
\text { exceeds limit } \\
\text { reference } \\
\text { points }(\%)\end{array}$} \\
\hline & & $F_{0.1}$ & $F_{\mathrm{SSB} 40}$ & $F_{\max }$ & $F_{\text {SSB25 }}$ & $\begin{array}{c}F_{\text {current }} \\
>F_{0.1}\end{array}$ & $\begin{array}{c}F_{\text {current }} \\
>F_{\mathrm{SSB} 40}\end{array}$ & $\begin{array}{c}F_{\text {current }} \\
>F_{\text {max }}\end{array}$ & $\begin{array}{l}F_{\text {current }} \\
>F_{\text {SSB } 25}\end{array}$ \\
\hline S1 & $0.85(0.82-0.89)$ & $0.96(0.95-0.98)$ & $0.82(0.78-0.85)$ & $2.22(2.18-2.26)$ & $1.57(1.48-1.65)$ & $18 \%$ & $53 \%$ & $0 \%$ & $4 \%$ \\
\hline S2 & $0.80(0.77-0.83)$ & $0.95(0.94-0.96)$ & $0.81(0.77-0.85)$ & $2.22(2.18-2.26)$ & $1.55(1.46-1.65)$ & $11 \%$ & $43 \%$ & $0 \%$ & $2 \%$ \\
\hline F1 & $0.80(0.77-0.83$ & $0.96(0.95-0.98)$ & $0.87(0.84-0.91)$ & $2.32(2.27-2.37)$ & $1.72(1.63-1.81)$ & $8 \%$ & $29 \%$ & $0 \%$ & $2 \%$ \\
\hline F2 & $0.81(0.78-0.84)$ & $1.03(1.02-1.05)$ & $0.86(0.82-0.90)$ & $2.28(2.24-2.32)$ & $1.65(1.55-1.74)$ & $2 \%$ & $36 \%$ & $0 \%$ & $3 \%$ \\
\hline F3 & $0.87(0.83-0.90)$ & $1.07(1.05-1.08)$ & $0.96(0.92-0.99)$ & $2.46(2.41-2.50)$ & $1.89(1.80-1.99)$ & $7 \%$ & $27 \%$ & $0 \%$ & $2 \%$ \\
\hline F4 & $0.82(0.80-0.85)$ & $1.00(0.99-1.02)$ & $0.93(0.89-0.97)$ & $2.40(2.36-2.44)$ & $1.94(1.82-2.05)$ & $9 \%$ & $32 \%$ & $0 \%$ & $0 \%$ \\
\hline
\end{tabular}

for targeting large marlins (Istiophoridae) and light tackle and smaller terminal equipment used to specifically target wahoo and similar-size mackerels and tunas. In addition to fishing gear, there are spatiotemporal differences in fishing effort between fishing sectors because the majority of fishing effort in the recreational fishery is expended during the day in more southern areas of the EEZ that are relatively close to the coast (Zischke et al., 2012). Therefore, differences in the size (and age) distributions of wahoo caught by commercial and recreational fisheries off eastern Australia may be due to the spatiotemporal differences in fishing areas between sectors (cf., Griffiths, 2010), rather than due to the selectivity of fishing gears, particularly if wahoo of different sizes or ages display different spatial distributions. It is important to quantify fishery-specific selectivity probabilities for stock assessment and to understand how potential management changes might influence selectivity.

\section{Per-recruit analysis}

Dynamic pool models and virtual population analysis can be useful in situations (e.g., in developing fisheries) in which there are little historical catch and effort data (Gabriel and Mace, 1999). We provided an assessment of $F_{\text {current }}$ against a traditional limit reference point $F_{\text {max }}$. However, because per-recruit models assume constant recruitment regardless of spawning stock size, estimates of $F_{\max }$ may not be sufficient to ensure sustainability (Gabriel and Mace, 1999). We also estimated $F_{0.1}$, a precautionary target reference point that may reduce the chance of overfishing and stock col- lapse, particularly in data-poor fisheries (Gulland and Boerema, 1973). Constant recruitment is assumed in a yield-per-recruit model and therefore is independent of variations in stock size, and recruitment overfishing is not able to be detected (Quinn and Deriso, 1999). We investigated recruitment overfishing by conducting an SBB/R analysis to assess $F_{\text {current }}$ against a limit reference point of $F_{\mathrm{SSB} 25}$ and a target reference point of $F_{\text {SSB40 }}$ (Goodyear, 1993).

Current levels of $F$ of wahoo in the southwest $\mathrm{Pa}$ cific Ocean are below both limit $\left(F_{\max }\right)$ and target $\left(F_{0.1}\right)$ reference points for $\mathrm{Y} / \mathrm{R}$ and the limit reference point $\left(F_{\mathrm{SSB} 25}\right)$ for $\mathrm{SSB} / \mathrm{R}$, but they are similar to the target reference point $\left(F_{\mathrm{SSB} 40}\right)$ for SSB/R (Table 2 ; Fig. 4$)$. This finding indicates that, under current fishing practices in commercial and recreational fisheries, wahoo may be at higher risk of recruitment overfishing than of growth overfishing-an observation that may be attributed to their fast growth and the low selectivity of juvenile fish by fisheries. Chale-Matsau et al. (1999) obtained similar results from a per-recruit analysis of the closely related Kanadi kingfish (Scomberomorus plurilineatus) in South Africa; in that study, $F_{0.1}$ greatly exceeded $F_{\text {SSB50, }}$, and the authors suggested that $F_{\text {SSB50 }}$ be used as a biological reference point for that species as a safeguard to minimize the risk of recruitment overfishing.

\section{Sensitivity and management simulations}

The iterative approach to the per-recruit model allowed us to explore the likelihood that $F_{\text {current }}$ exceeded reference points because of uncertainty in biological param- 

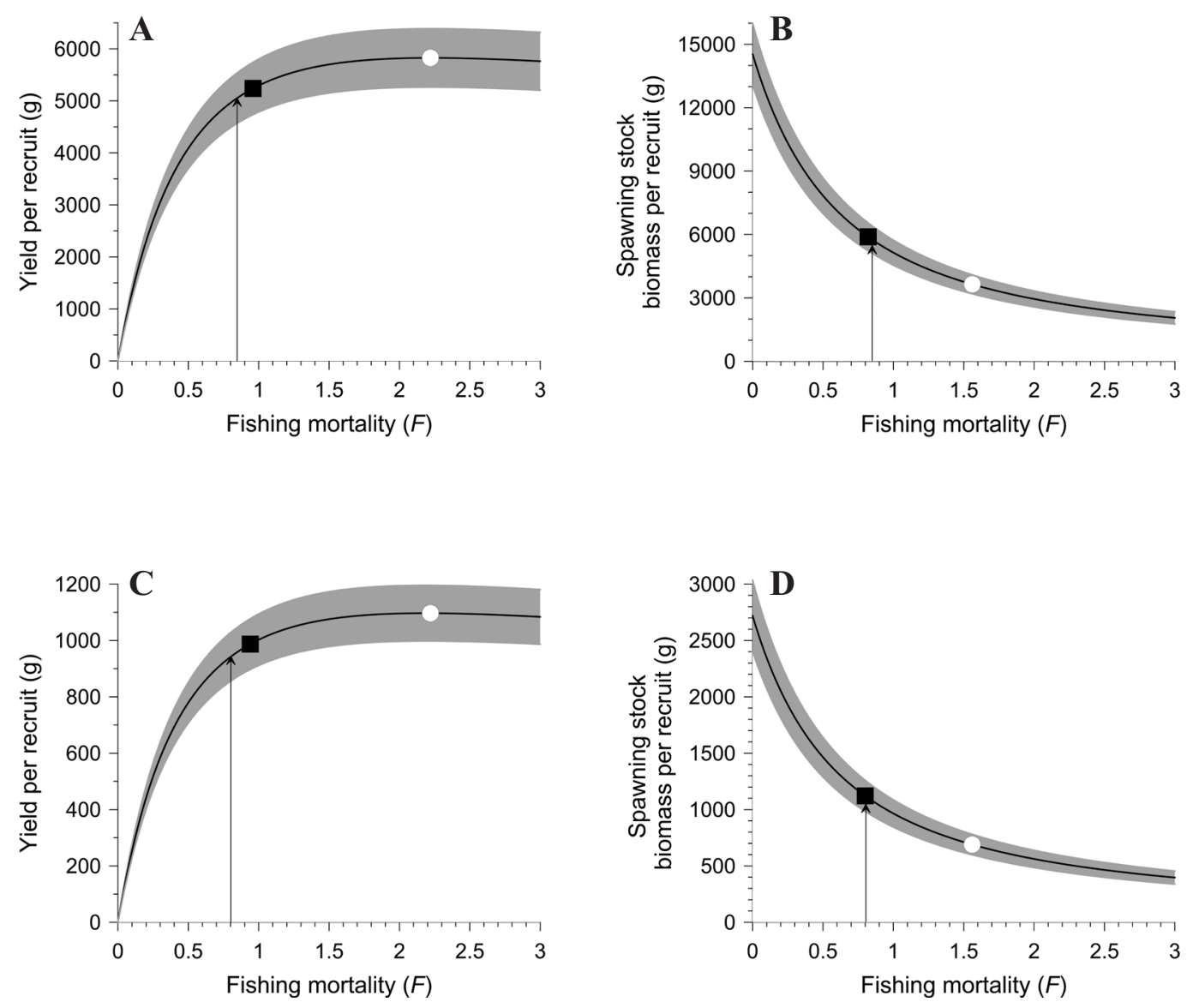

Figure 4

Mean estimates (solid line) and 95\% confidence intervals (gray shaded area) of yield per recruit (Y/R) and spawning stock biomass per recruit (SSB/R) for wahoo (Acanthocybium solandri) in the southwest Pacific Ocean during 2008-2010: (A) Y/R and (B) SSB/R for a model scenario with constant natural mortality for all ages (scenario 1 [S1]; see Materials and methods section) and (C) Y/R and (D) SSB/R for a model scenario where natural mortality is 10-fold higher for juvenile fish than for adults (S2; see Materials and methods section). Arrows indicate current fishing mortality. Black squares represent target reference points of fishing mortality at which the slope of the Y/R curve is $10 \%$ of the slope at the origin in panels $\mathrm{A}$ and $\mathrm{C}$ and target reference points of fishing mortality at which the SSB/R is $40 \%$ of the SSB/R at $F=0$ in panels B and D. Open circles represent limit reference points of fishing mortality at which maximum $\mathrm{Y} / \mathrm{R}$ is produced in panels $\mathrm{A}$ and $\mathrm{C}$ and reference points of fishing mortality at which the SSB/R is $25 \%$ of the SSB/R at $F=0$ in panels in B and D.

eters. The base scenario (S1), including variability in growth and maturity parameters, resulted in $95 \%$ confidence intervals of approximately $10 \%$ for both $\mathrm{Y} / \mathrm{R}$ and SSB/R. Although recent research has provided the most reliable account of wahoo growth dynamics (Zischke et al., 2013b), further biological research is needed to validate the periodicity of growth increment formation to ensure that length-at-age relationships used in future assessments are reliable. Future assessment of wahoo stocks should prioritize research that provides regional estimates of growth parameters. Similar effects of variability in age and growth have been shown for walleye pollock (Gadus chalcogrammus) in the eastern Bering
Sea, where aging error has had little effect on estimates of growth and mortality but has produced sufficiently different results in a Y/R analysis conducted to infer overfishing (Lai and Gunderson, 1987).

The iterative approach also allowed us to assess the impact of potential management changes on $\mathrm{Y} / \mathrm{R}$ and SSB/R. For example, $F_{\text {current }}$ exceeded $F_{\text {SSB } 40}$ in $53 \%$ of iterations under the standard scenario (S1), but this percentage decreased to $27 \%$ when a slot limit in the recreational fishery was introduced (F3; Table 2). Overall, fishery management scenarios (F1-F4) had little effect on the results of the per-recruit model because $F_{\text {current }}$ was already lower than 3 (and similar to 1 ) of 
the reference points in the base scenario (S1). A similar outcome was seen in a per-recruit analysis of longtail tuna ( $T$. tonggol) in Australian waters, whereby increases in recreational size limits and post-release survival did not change the relationship between $F_{\text {cur- }}$ rent and biological reference points (Griffiths, 2010). It is likely that this finding results from low selectivity of immature fish of both species in recreational fisheries. In contrast, the recreational fishery for largemouth queenfish (Scomberoides commersonnianus) in Australian waters had a relatively high selectivity for immature fish; therefore, increasing minimum size limits to reflect $L_{50}$ had a drastic improvement on the status of that stock (Griffiths et al., 2006).

\section{Future directions}

We compared $F_{\text {current }}$ for wahoo against traditionally used reference points for target species in commercial fisheries. Alternative reference points, such as catch rate, mortality rate, and potential biological removal, have been suggested for data-poor bycatch species (Moore et al., 2013). However, because wahoo represent an important byproduct in the 2 commercial fisheries assessed in this article, reference points based on yield may still be appropriate. Management objectives for recreational fisheries, which generally value high catch rates and large average size of fish, differ from those for commercial fisheries, which value total yield and high profit. In regions where recreational fisheries represent a significant proportion of total $F$ for wahoo, alternative reference points that reflect the preferences of these fisheries (e.g. more large fish) may be appropriate.

Per-recruit analysis cannot directly explore the effect of reducing catch and effort on the status of a stock. However, input (effort-based) and output (catchbased) management measures are commonly used in both commercial and recreational fisheries. For example, the efficacy of current commercial trip limits or recreational possession limits for wahoo could not be examined with per-recruit analysis. A population model should be adopted in future assessments of this species in the southwest Pacific Ocean, such as MULTIFAN-CL (Fournier et al., 1998; Kleiber et al., 2003), that is structured by size, age, and spatial distribution. This model can integrate fishery-specific catch, effort, and length-frequency data, as well as tag and release data, to provide time-series estimates of recruitment, biomass, and $F$, as well as to summarize the stock status against various reference points.

This approach has been used extensively for pelagic target species in commercial fisheries throughout the western and central Pacific Ocean (Davies et al. ${ }^{9}$; Hoyle

\footnotetext{
${ }^{9}$ Davies, N., S. Hoyle, S. Harley, A. Langley, P. Kleiber, and J. Hampton. 2011. Stock assessment of bigeye tuna in the western and central Pacific Ocean. Western and Central Pacific Fisheries Commission WCPFC-SC7-2011/SA- WP-02, 119 p. [Available at website.]
}

et al. ${ }^{10}$; Langley et al. ${ }^{11}$ ). Although such assessments are data intensive and, therefore, costly to implement, they allow management strategy evaluations to explore outcomes for fishery and population sustainability objectives. Alternatively, cost-effective methods for assessing all species that a fishery interacts with, such as the quantitative ecological sustainability assessment for fishing effects developed by Zhou and Griffiths (2008), may be more appropriate for wahoo and other byproduct and bycatch species.

Although wahoo may still be considered a low-priority species for most commercial fisheries, their steadily increasing catches worldwide may require species-specific management in the future. We collated biological and fishery information for wahoo in the southwest Pacific Ocean and present the first quantitative assessment of their status in this region. The results of this assessment indicate that $F_{\text {current }}$ for wahoo is lower than limit reference points and the target reference point for $\mathrm{Y} / \mathrm{R}$ and that it is slightly higher than the target reference point for SBB/R. It is important that these fisheries be re-assessed periodically because their dynamics (e.g., effort, catch, or management arrangements) may change through time. In addition to providing a baseline assessment for wahoo, this study provides an approach that may be useful for data-poor, nontarget species in other fisheries worldwide.

\section{Acknowledgments}

We thank the Australian Fisheries Management Authority and Secretariat of the Pacific Community for providing catch, effort and, size-frequency data from commercial fisheries. We would like to thank 3 anonymous reviewers for constructive feedback that improved the quality of the final manuscript. We also thank I. Tibbetts (UQ) for comments on an earlier draft of the manuscript. M.T.Z was funded by a University of Queensland Research Scholarship, with support provided by the Division of Marine and Atmospheric Research of the Commonwealth Scientific and Industrial Research Organisation.

\section{Literature cited}

Beverton, R. J. H., and S. J. Holt.

1957. On the dynamics of exploited fish populations, 533 p. Chapman \& Hall, London.

Chale-Matsau, J. R., A. Govender, and L. E. Beckley. 1999. Age and growth of the queen mackerel Scomb-

\footnotetext{
${ }^{10}$ Hoyle, S., J. Hampton, and N. Davies. 2012. Stock assessment of albacore tuna in the South Pacific Ocean. Western and Central Pacific Fisheries Commission WCPFC-SC8-2012/ SA-WP-04-REV1, 123 p. [Available at website.]

${ }^{11}$ Langley, A., S. Hoyle, and J. Hampton. 2011. Stock assessment of yellowfin tuna in the western and central Pacific Ocean. Western and Central Pacific Fisheries Commission WCPFC-SC7-2011/SA- WP-03, 124 p. [Available at website.]
} 
eromorus plurilineatus from KwaZulu-Natal, South Africa. Fish. Res. 44:121-127. Article

Collette, B. B., and C. E. Nauen.

1983. FAO species catalogue, vol. 2. Scombrids of the world. FAO Fish. Synop. 125, 137 p. FAO, Rome.

Curran, D., and K. Bigelow.

2011. Effects of circle hooks on pelagic catches in the Hawaii-based tuna longline fishery. Fish. Res. 109:265-275. Article

Domeier, M. L., H. Dewar, and N. Nasby-Lucas.

2003. Mortality rate of striped marlin (Tetrapturus audax) caught with recreational tackle. Mar. Freshw. Res. 54:435-445. Article

Fournier, D. A., J. Hampton, and J. R. Sibert.

1998. MULTIFAN-CL: a length-based, age-structured model for fisheries stock assessment, with application to South Pacific albacore, Thunnus alalunga. Can. J. Fish. Aquat. Sci. 55:2105-2116. Article

Gabriel, W. L., and P. M. Mace.

1999. A review of biological reference points in the context of the precautionary approach. In Proceedings of the fifth national NMFS stock assessment workshop: providing scientific advice to implement the precautionary approach under the Magnuson-Stevens Fishery Conservation and Management Act; Key Largo, FL, 24-26 February 1998 (V. R. Restrepo, ed.), p. 34-45. NOAA Tech Memo NMFS-F/SPO-40.

Goodyear, C. P.

1993. Spawning stock biomass per recruit in fisheries management: foundation and current use. In Risk evaluation and biological reference points for fisheries management (S. J. Smith, J. J. Hunt, and D. Rivard, eds.), p. 67-81. Can. Spec. Publ. Fish. Aquat. Sci. 120.

Griffiths, S. P.

2010. Stock assessment and efficacy of size limits on longtail tuna (Thunnus tonggol) caught in Australian waters. Fish. Res.102:248-257. Article

Griffiths, S. P., G. C. Fry, and T. D. van der Velde.

2006. Population dynamics and fishery benefits of a large legal size of a pelagic sportfish, the Talang queenfish, Scomberoides commersonnianus, in northern Australia. Fish. Res. 83:74-86. Article

Gulland, J. A., and L. K. Boerema.

1973. Scientific advice on catch levels. Fish. Bull. 71:325-335.

Hampton, J.

2000. Natural mortality rates in tropical tunas: size really does matter. Can. J. Fish. Aquat. Sci. 57:1002-1010. Article

Hoenig, J. M.

1983. Empirical use of longevity data to estimate mortality rates. Fish. Bull. 82:898-903.

Hovgard, H., and H. Lassen.

2000. Manual on estimation of selectivity for gillnet and longline gears in abundance surveys. FAO Fish. Tech. Paper 397, $84 \mathrm{p}$.

Kerstetter, D. W., and J. E. Graves.

2006. Survival of white marlin (Tetrapturus albidus) released from commercial pelagic longline gear in the western North Atlantic. Fish. Bull. 104:434-444.

2008. Postrelease survival of sailfish caught by commercial pelagic longline gear in the southern Gulf of Mexico. N. Am. J. Fish. Manage. 28:1578-1586. Article
Kleiber, P., J. Hampton, and D. A. Fournier. 2003. MULTIFAN-CL User's Guide, 152 p. [Available at website.]

Lai, H. L., and D. R. Gunderson.

1987. Effects of ageing errors on estimates of growth, mortality and yield per recruit for walleye pollock (Theragra chalcogramma). Fish. Res. 5:287-302.

Lee, T. M.

2008. Estimation of life history parameters, biological reference points, and associated uncertainties for wahoo (Acanthocybium solandri) in the waters off eastern Taiwan. M.S. thesis, 75 p. National Taiwan Univ., Taipei, Taiwan.

Moore, J. E., K. A. Curtis, R. L. Lewison, P. W. Dillingham, J. M. Cope, S. V. Fordham, S. S. Heppell, S. A. Pardo, C. A. Simpfendorfer, G. N. Tuck, and S. Zhou.

2013. Evaluating sustainability of fisheries bycatch mortality for marine megafauna: a review of conservation reference points for data-limited populations. Environ. Conserv. 40:329-344. Article

Pauly, D.

1980. On the interrelationships between natural mortality, growth parameters, and mean environmental temperature in 175 fish stocks. J. Cons. 39:175-192.

1983. Length-converted catch curves: a powerful tool for fisheries research in the tropics (Part I). Fishbyte 1:9-13.

1984a. Length-converted catch curves: a powerful tool for fisheries research in the tropics (III: Conclusion). Fishbyte 2:9-10.

1984b. Length-converted catch curves: a powerful tool for fisheries research in the tropics (Part II). Fishbyte 2:17-19.

Quinn, T. J., and R. B. Deriso.

1999. Quantitative fish dynamics, 560 p. Oxford Univ. Press, New York.

$\mathrm{R}$ Core Team.

2013. R: a language and environment for statistical computing. R Foundation for Statistical Computing, Vienna, Austria. [Available at website, accessed October 2013]

Sepulveda, C. A., S. A. Aalbers, S. Ortega-Garcia, N. C. Wegner, and D. Bernal.

2011. Depth distribution and temperature preferences of wahoo (Acanthocybium solandri) off Baja California Sur, Mexico. Mar. Biol. 158:917-926. Article

Skomal, G. B., B. C. Chase, and E. D. Prince.

2002. A comparison of circle hook and straight hook performance in recreational fisheries for juvenile Atlantic bluefin tuna. Am. Fish. Soc., Symp. 30:57-65.

Sparre, P., E. Ursin, and S. C. Venema.

1989. Introduction to tropical fish stock assessment. Part 1. Manual. FAO Fish. Tech. Pap. 306.1, 337 p. FAO, Rome.

Theisen, T. C.

2007. Population genetic structure, movement patterns, and environmental preferences of the pelagic wahoo, Acanthocybium solandri. Ph.D. thesis, 98 p. Florida Atlantic Univ., Boca Raton, FL.

Theisen, T. C., B. W. Bowen, W. Lanier, and J. D. Baldwin.

2008. High connectivity on a global scale in the pelagic wahoo, Acanthocybium solandri (tuna family Scombridae). Mol. Ecol. 17:4233-4247. Article

Vetter, E. F.

1988. Estimation of natural mortality in fish stocks: a review. Fish. Bull. 86:25-43. 
Zhou, S. and S. P. Griffiths.

2008. Sustainability Assessment for Fishing Effects (SAFE): a new quantitative ecological risk assessment method and its application to elasmobranch bycatch in an Australian trawl fishery. Fish. Res. 91:56-68. Article

Zischke, M. T.

2012. A review of the biology, stock structure, fisheries and status of wahoo (Acanthocybium solandri), with reference to the Pacific Ocean. Fish. Res. 119-120:13-22. Article

Zischke, M. T., J. H. Farley, S. P. Griffiths, and I. R. Tibbetts. 2013a. Reproductive biology of wahoo, Acanthocybium solandri, off eastern Australia. Rev. Fish Biol. Fish. 23:491-506. Article
Zischke, M. T., S. P. Griffiths, and I. R. Tibbetts.

2012. Catch and effort from a specialised recreational pelagic sport fishery off eastern Australia. Fish. Res. 127-128:61-72. Article

2013b. Rapid growth of wahoo (Acanthcybium solandri) in the Coral Sea, based on length-at-age estimates using annual and daily increments on sagittal otoliths. ICES J. Mar. Sci. 70:1128-1139. Article

Zischke, M. T., S. P. Griffiths, I. R. Tibbetts, and R. J. G. Lester. 2013c. Stock identification of wahoo (Acanthocybium solandri) in the Pacific and Indian Oceans using morphometrics and parasites. ICES J. Mar. Sci. 70:164-172. Article 